\title{
Evaluation of Strength and Durability of Geo Polymer Concrete
}

\author{
Geena George ${ }^{1}$ \\ Associate Professor, Department of Civil Engineering \\ E,P.C.E.T, \\ Bangalore, India
}

\author{
Chaithra $\mathrm{P}^{2}$ \\ PG Student, Department of Civil Engineering, \\ EPCET, \\ Bangalore, India
}

\begin{abstract}
It is important to durable of structure and reduce CO2 emission through the greater use of substitute for Cement. The use of supplementary cementitious materials as partial replacements for the cement in concrete will play a significant role with respect to the environmental control of greenhouse effects and global temperature reduction. The development of geopolymer concrete (GPC), processing of geopolymer using fly ash, GGBS in combination with sodium hydroxide and sodium silicate solutions, offers a promising alternative to ordinary portland cement concrete. This study compares the different ratios of fly ash to GGBS where, 50:50,60:40,40:60 ratios and differing the molarities of alkaline solutions which are $8 \mathrm{M}, 10 \mathrm{M}$ and $12 \mathrm{M}$ and comparing the strengths of the above ratios and conducting durability characteristics of fly ash and GGBS based geopolymer concrete by conducting test procedures like acid attack test
\end{abstract}

\section{Keywords - Geo polymer concrete,Fly ash,GGBS,Durability}

\section{INTRODUCTION}

In this modern world, the most used raw material for construction of buildings these used material in concrete is normally manufactured mixing the ingredients such as cement, fine aggregate, coarse aggregate and water, mineral admixtures for the concrete nowadays such as ,fly ash, GGBS and also usage of super plasters for improving strength of concrete. The materials used for concrete manufactures such as fine aggregates are found in nature but the materials like cement has to be manufactured by using the various raw materials for the manufacture of cement is energy consuming process and also it produces large amount of green house gases like carbon dioxide etc which will affects the global warming hence to reduce the use of the cement in concrete the researchers started their research[2] . in the year 1978 , Davidovits proposed that the binder can be obtained by using the alkaline solution in the concrete by using the alkaline solution in the concrete the polymerization process will occur in the concrete and creates thebond between the concrete hence this concrete is called as geopolymer concrete instead of cement we can use other cementitious materials like fly ash , ground granulated blast furnace slag and metallergic slag these are the admixtures which are obtained due to the industrial wastes and which also reduces the pollution of the environment. [1]The geopolymer concrete is to be such that it should obtain high strength and also the geopolymer concrete should be durable. The durable concrete means the concrete should provide greater resistance towards the weathering action, acid attacks and freeze and thaw cycles., deterioration and exposed to the harsh environment

In this project I have used different ratios of fly ash to GGBS which are 60:40,40:60 and 50:50 of 100 percent replacement of cement. In the current study on GPC are mainly focused on geopolymer technology to make fly ash and ground granulated blast furnace slag based geopolymer concrete and determination of its properties[5]

\section{GEOPOLYMER CONCRETE}

Geopolymer concrete is made up of source materials, fly ash, GGBS, and alkali liquids which are the combination of sodium silicate $\left(\mathrm{NaSio}_{3}\right)$ and sodium hydroxide $(\mathrm{NaOH})$ which form the binder due to the polymerization process. The binders created were termed as "geopolymers". Unlike ordinary Portland or pozzolanic cements, geopolymers do not form calcium-silicate-hydrates for matrix formation and strength, but the aluminosilicate gel formed by geopolymerization binds the aggregates and provides the strength to geopolymer concrete. Source materials and alkaline liquids are the two main constituents of geopolymers, the strengths of which depend on the nature of the materials and the types of liquids. Materials containing silicon and aluminium in amorphous form, which come from natural minerals or by-product materials, could be used as source materials for geopolymers. Kaolinite, clays, etc., are included in the natural minerals group whereas fly ash, silica fume, slag, rice-husk ash, red mud, etc., are by-product materials. For the manufacture of geopolymers,[4] the choice of source materials depends mainly on their availability and cost, the type of application and the specific demand of the users. Metallurgical slag was also used as a raw material to make geopolymer and it was found that the addition of slag enhanced the properties of the geopolymer. Among the available raw materials, fly ash has attracted more attention due to its ability in improving geopolymer physical properties and its availability in large quantities . However high compressive strength geopolymer composite was obtained at elevated temperatures curing which restricts its application to precast elements The manufacture of this new concrete follows the same production technology methods as in the case of OPC. [7]Nonetheless, whether it is geopolymer or Portland cement, concrete is a porous material, and concrete structures must be able to resist to physical, mechanical and chemical aggressions from their environment throughout their lifetime. 


\section{MATERIALS}

\section{A. FLY ASH}

Fly ash is a by-product collected in the de-dusting of gases derived from the combustion of pulverized coal used in power plants. Fly ash is composed of fine particles, and its chemical composition is related to the different types and relative amounts of incombustible materials present in the coal. Fly ash particles are typically spherical, ranging in diameter from less than $1 \mu \mathrm{m}$ to no more than $150 \mu \mathrm{m}$ (Malhotra, Concrete Construction Engineering Handbook, 2008). Generally, its constitutive elements are: aluminum, silicon, calcium, magnesium, and iron. Thus, depending on the combustion process and the type of combustible, the ash can be silica, sand-lime or lime sulfur, in some cases with pozzolanic and hydraulic properties. Referring to the pozzolanic activity shown by fly ashes, the American Society for Testing and Materials (ASTM C125, 1975) defines a pozzolan as "a siliceous or siliceous and aluminous material which in itself possesses little or no cementitious value, but which will, in finely divided form and in the presence of moisture, chemically react with calcium hydroxide at ordinary temperature to form compounds possessing cementitious properties". Basically, the great interest for the use of fly ashes comes from their ability to react with calcium hydroxide to form calcium silicate hydrates which possess pozzolanic and hydraulic properties

TABLE 1: Physical propertiesof fly ash

\begin{tabular}{|l|l|l|}
\hline Sl no & Physical properties & Fly ash \\
\hline 1 & Specific gravity & 2.26 \\
\hline 2 & fineness & $6.8 \%$ \\
\hline
\end{tabular}

\section{B. GROUND GRANULATED BLAST FURNACE SLAG}

Ground granulated blast furnace slag (GGBS) is a byproduct given from the steel industry. Blast furnace slag is defined as "the non metallic product consisting essentially of calcium silicates and other bases that is to be developed in a molten condition simultaneously with iron and blast furnace to use as a cementitious material the GGBS must be ground as finer than the cement . the fineness of grind will determine how rapidly the slag will react in the concrete. In our project we are not using normal cement(OPC). are completely replacing cement with the fly ash and GGBS to make it completely a green concrete.The propotions of fly ash and GGBS can be seen in further chapters. The chemical composition of slag will vary depending upon source of raw materials and the blast furnace conditions. The major oxides exist within the slag in the form of a network of calcium, silicon, aluminium and magnesium ions in disordered combination with oxygen.

\begin{tabular}{|l|l|l|}
\multicolumn{1}{|c}{ TABLE 2Physical propertiesof GGBS } \\
\begin{tabular}{|lr|l|}
\hline SI No & Physical properties & GGBS \\
\hline 1 & Specific gravity & 2.13 \\
\hline 2 & Fineness & $4.3 \%$ \\
\hline
\end{tabular}
\end{tabular}

\section{ACTIVATOR SOLUTION}

The alkali solution is used for alkalination of GGBS thus leading to polymerization which results in geopolymer binder. Sodium hydroxide and sodium silicate is used as mediums to form alkali solutions. Different concentrations of
$\mathrm{NaOH}$ solution were prepared in the Lab. Sodium silicate of $40 \%$ concentration and required grade was added to sodium hydroxide solution and the alkali solution was prepared .Sodium silicate are colourless glassy or crystalline or white powders in form. Na2SiO3 are stable alkaline solutions This solution was prepared 1 day prior to be used and consumed within 36 hours. The solution was prepared and it should be kept covered at room temperature for gel formation

\section{METHODOLOGY}

The fly ash and GGBS based geopolymer concrete specimens (GPC) were prepared with an alkaline solution ratio (sodium silicate to sodium hydroxide) of 2 by mass, since the strength was maximum, when the ratio of sodium hydroxide and sodium silicate was 2 .. The grades of concrete chosen were based on IS 456-2000. The molarity of sodium hydroxide was varied as $8 \mathrm{M}, 10 \mathrm{M}$ and $12 \mathrm{M}$. the ratio of GGBS and Fly ash is taken as 50:50. The cube specimen of size $150 \mathrm{~mm} \times 150 \mathrm{~mm} \times 150 \mathrm{~mm}$ were casted .after casting the specimens the are kept in sun for 1 day. Then specimens were kept in the solution consists of $1 \%$ of $0.05 \mathrm{~N} \mathrm{MgSO}_{4}$ and $0.25 \%$ of $1 \mathrm{~N} \mathrm{H}_{2} \mathrm{SO}_{4}$ solution for 14 days, 28 days and 56 days . after these time period the cubes were tested according to visibility ,mass change and strength test. Then this has been compared with the OPC concrete

\section{MIX PROPOTIONS}

\section{DESIGN MIX}

Mix design for M30 cement concrete as per IS 10262:2009 was prepared as control mix with ratio of 1:1.5:2.5 and 0.4 w/c ratio. The control specimens were water cured for 28 days.

\section{E. GEOPOLYMER MIX}

In geopolymer mix there is a several mixes according to the propotion of GGBS to fly ash has a binding material and varying concentrations of $\mathrm{NaOH}$ in the alkali actiator solution.

The mixes are shown in the below table. 3

TABLE 3 Quantities of materials required for geopolymer concrete with varing in concentration of alkaline solution:

\begin{tabular}{|c|c|c|c|c|c|c|c|c|}
\hline \multicolumn{3}{|c|}{8 Molarity } & \multicolumn{3}{|c|}{10 Molarity } & \multicolumn{3}{|c|}{12 Molarity } \\
\hline Mix & $\begin{array}{l}\text { Fly } \\
\text { ash }\end{array}$ & $\begin{array}{l}\text { GG } \\
\text { BS }\end{array}$ & Mix & $\begin{array}{l}\text { Fly } \\
\text { ash }\end{array}$ & $\begin{array}{l}\text { GG } \\
\text { BS }\end{array}$ & Mix & $\begin{array}{l}\text { Fly } \\
\text { ash }\end{array}$ & GGBS \\
\hline \multirow{2}{*}{$\begin{array}{c}\text { M8. } \\
1\end{array}$} & $40 \%$ & $60 \%$ & \multirow{2}{*}{$\begin{array}{c}\text { M10 } \\
.1\end{array}$} & $40 \%$ & $60 \%$ & \multirow{2}{*}{$\begin{array}{c}\text { M12. } \\
1\end{array}$} & $40 \%$ & $60 \%$ \\
\hline & 240 & 360 & & 240 & 360 & & 240 & 360 \\
\hline \multirow{2}{*}{$\begin{array}{c}\text { M8. } \\
2\end{array}$} & $50 \%$ & $50 \%$ & \multirow{2}{*}{$\begin{array}{c}\text { M10 } \\
.2\end{array}$} & $50 \%$ & $50 \%$ & \multirow{2}{*}{$\begin{array}{c}\text { M12. } \\
2\end{array}$} & $50 \%$ & $50 \%$ \\
\hline & 300 & 300 & & 300 & 300 & & 300 & 300 \\
\hline \multirow{2}{*}{$\begin{array}{c}\text { M8. } \\
3\end{array}$} & $60 \%$ & $40 \%$ & \multirow{2}{*}{$\begin{array}{c}\text { M10 } \\
.3\end{array}$} & $60 \%$ & $40 \%$ & \multirow{2}{*}{$\begin{array}{c}\text { M12. } \\
3\end{array}$} & $60 \%$ & $40 \%$ \\
\hline & 360 & 240 & & 360 & 240 & & 360 & 240 \\
\hline
\end{tabular}

\section{RESULTS \& DISCUSSION}

\section{A.COMPRESSION STRENGTH OF GPC}

For the compression test we have casted $8 \mathrm{M}, 10 \mathrm{M}$ and $12 \mathrm{M}$ geopolymer concrete cubes of size $150 \mathrm{mmx} 150 \mathrm{mmx} 150 \mathrm{~mm}$. after casting cubes it has been kept in a sunlight for 3daysat ambient temperature curing.After this the cubes were tested for compression test From the literature it is known that the 
Geopolymer concrete will obtain $99.99 \%$ strength within 3 days hence in this project have tested the cubes after 3 days for its strength

TABLE 4Compression strength values of 12M NaOH Cubes
\begin{tabular}{|c|c|c|}
\hline GGBS and fly ash & load(KN) & strength \\
\hline \multicolumn{3}{|c|}{$\mathbf{8 M}$} \\
\hline M8.1 & 713 & 31.7 \\
\hline M8.2 & 756 & 33.6 \\
\hline M8.3 & 868 & 38.6 \\
\hline \multicolumn{3}{|c|}{$\mathbf{1 0 M}$} \\
\hline M10.1 & 873 & 38.8 \\
\hline M10.2 & 913 & 45.6 \\
\hline M10.3 & 1093 & 48.6 \\
\hline \multicolumn{3}{|c|}{12 M } \\
\hline M12,1 & 1016 & 45.17 \\
\hline M12,2 & 1098 & 48.8 \\
\hline M12,3 & 1248 & 55.47 \\
\hline
\end{tabular}

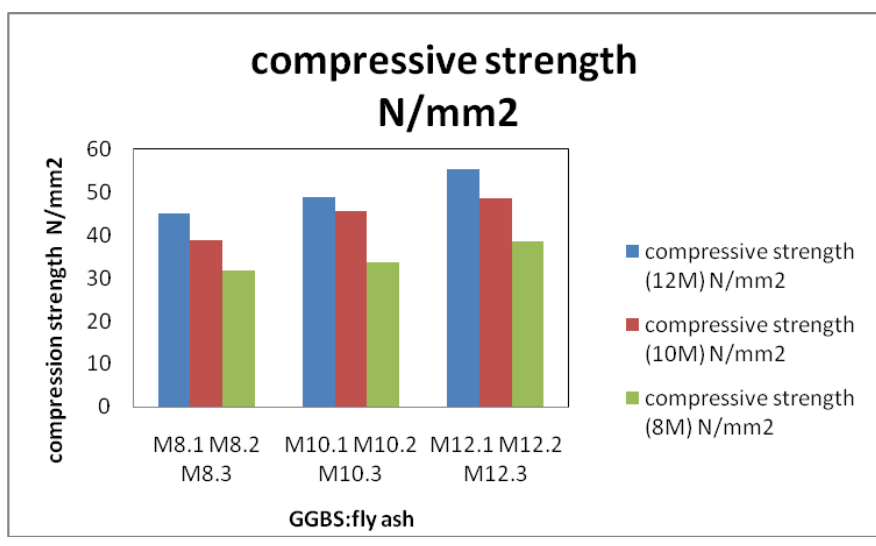

Fig. 1. Comparison graph for compressive strength for $8 M, 10 M$ and $12 M$ concentration of $\mathrm{NaOH}$ in Geopolymer concrete

Figure 1 shows the comparison of compression strength of $8 \mathrm{M}, 10 \mathrm{M}$ and $12 \mathrm{M}$ concentration of $\mathrm{NaOH}$ geopolymer cubes in which the $12 \mathrm{M}$ concentration geopolymer cubes shows the high strength from this we can conclude that as the concentration of the $\mathrm{NaOH}$ in concrete increases the strength of the concrete also increases gradually.hence for further studies using 50:50 ratio that is GGBS to fly ash ratio with varying concentrations of $\mathrm{NaOH}$ GPC cubes

\section{B. DURABILITY OF GEOPOLYMER CONCRETE.}

Durability of the concrete is defined as the ability of which it produces resistance towards the weathering action, chemical attack, abrasion and freezing and thawing cyclesTo check the durability of the cycles To check the durability of the geopolymer concrete in this paper have conducted chemical attack test i.e., sulfate attack test .

The specimens of size $150 \mathrm{~mm} \times 150 \mathrm{~mm} \times 150 \mathrm{~mm}$ were kept in the solution consists of $1 \%$ of $0.05 \mathrm{~N} \mathrm{MgSO}_{4}$ and $0.25 \%$ of $1 \mathrm{~N} \mathrm{H}_{2} \mathrm{SO}_{4}$ solution for 14 days, 28days and 56days . after these time period the cubes were tested according to visibility ,mass change and strength test. Then this has been compared with the OPC concrete From sulphate attack test can find out which concrete produces the high resistance to the acid hence the durability of the concrete cannot be measured within the short time hence the concrete cubes has to be placed in the acid solution to minimum of 56 days and the durability of the concrete can be measured by visibility, change in colour and also the strength of the concrete Here both geopolymer concrete as well as the OPC has been compared and conclude which geopolymer concrete gives the high resistance towards the acids.

TABLE 5 Results of the durability test of Geopolymer concrete

\begin{tabular}{|c|c|c|c|}
\hline Concrete & Molarity & Days & $\begin{array}{l}\text { Compression } \\
\text { Strength }\left(\mathrm{N} / \mathrm{mm}^{2}\right)\end{array}$ \\
\hline \multirow{9}{*}{ GPC } & \multirow{3}{*}{8} & 14 & 35.68 \\
\hline & & 28 & 34.25 \\
\hline & & 56 & 33.55 \\
\hline & \multirow{3}{*}{10} & 14 & 45.55 \\
\hline & & 28 & 44.177 \\
\hline & & 56 & 43.15 \\
\hline & \multirow{3}{*}{12} & 14 & 46.66 \\
\hline & & 28 & 43.91 \\
\hline & & 56 & 43.33 \\
\hline \multirow[b]{3}{*}{ OPC } & \multirow{3}{*}{ - } & 14 & 42.17 \\
\hline & & 28 & 38.93 \\
\hline & & 56 & 35.86 \\
\hline
\end{tabular}

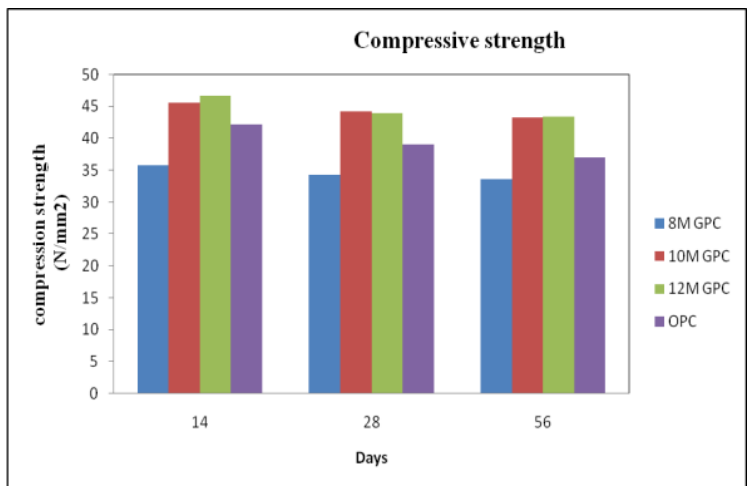

Fig 1 Comparison of the compressive strength of different concentrations of $\mathrm{NaOH}$ present in GPC cubes with conventional concrete.

As per the figure 2 can conclude that the geopolymer concrete which has been placed in the acid solution shows a gradual decrease of its strength but if compare to the normal OPC Concrete the resistance to acid attack is high in geopolymer concrete.Hence can conclude that geopolymer concrete shows greater durability than the normal concrete. The comparison graph shows the slight reduction in the strength of GPC concrete, 8M GPC concrete has reduced to $2.13 \%$ and $10 \mathrm{M}$ GPC concrete has reduced to $2.4 \%$ and $12 \mathrm{M}$ GPC has reduced to $3.33 \%$ and the OPC has reduced to $6.31 \%$.The reduction of strength is of $8 \mathrm{M} \mathrm{GPC}$ is less compared to other two GPC mixes hence the $8 \mathrm{M}$ geopolymer concrete shows high durability 


\section{CONCLUSION}

- F With increasing in the molarity of $\mathrm{NaOH}$ concentration the strength of GPC is also increasing

- The test results show the compressive strength of GPC with ambient curing temperature results in higher compressive strength.

- From test results it is observed that the compressive strength of GPC increases with the percentage of GGBS

- The test on compression strength show that 50:50 i.e., GGBS :fly ash has considered as optimum mix with better compression strength.

- The durability test values indicates that geopolymer concrete. ,shows better durability compared to normal concrete

\section{REFERENCES}

[1] Neethu Susan Mathew, S. Usha (2015), "concentrate on quality and solidness of fly ash and ggbfs based geopolymer concrete Universal Diary of Exploration in Designing and Innovation Volume: 02 Issue: $05 \mid "$.

[2] Jean-Baptiste Edouard .2011 "test assessment of the solidness of fly ash based geopolymer concrete in the marine condition".

[3] Urvashi Khandelwal Salmabanu Luhar Int.(2015)"Solidness Investigations of Fly ashBased Geopolymer Concrete".Diary of Building Exploration and Applications ISSN: 2248-9622, Vol. 5, Issue 8, (Section - 4), pp.17-32

[4] Anil Nis (2018)"Mechanical and strength properties of fly ash and slag based geopolymer concrete"Advances in Solid Development, Vol. 6, No. 4 (2018) 345-362 DOI: https://doi.org/10.12989/acc.2018.6.4.345 .

[5] N.S. Kumaravel, P. Girija (2015)sturdiness execution of different evaluation of geopolymer cement to opposition of corrosive and salt" asian diary of structural building (bhrc) vol. 16, no. 8 pages $1185-1191$

[6] R. Prasanna Venkatesan(2016) "Quality and strength properties of geopolymer concrete made with Ground Granulated Impact Heater Slag and Dark Rice Husk ash". KSCE Diary of Structural Designing volume 20, 